\title{
Education team of the year: innovative approaches to support better care
}

In this Feature (BMJ 2014;348:g1990, doi:10.1136/bmj.g1990), we misquoted Sebastian Mafeld, a radiological registrar at Freeman Hospital in Newcastle upon Tyne, in the section "UK Endovascular Trainees." The fifth sentence of this section should have read: "Five courses have been run, and 145 doctors trained, including - importantly, Mafeld says—-foundation trainees, who face early decisions about where to specialise and whose choice may be impaired by having no endovascular [not "endoscopic"] experience."

Cite this as: BMJ 2014;348:g2565

๑ BMJ Publishing Group Ltd 2014 